\title{
INCONGRUÊNCIAS NO DISCURSO SOBRE QUALIDADE DA EDUCAÇÃO BRASILEIRA
}

KATIA CRISTINA SILVA FORLI BAUTHENEY

\section{RESUMO}

Este artigo analisa, por um viés foucaultiano, as incongruências do discurso sobre qualidade da educação no Brasil a partir de dois instrumentos de aferição: o Índice de Desenvolvimento da Educação Básica e o Programa Internacional de Avaliação de Estudantes. Apesar do destaque para a necessidade de melhoria dos processos de escolarização, com avanço de discussões e sua constante inserção na agenda das políticas públicas em diversas esferas, o próprio sistema cria ciladas que podem comprometer a sua viabilização. Quando se simplifica a questão, por uma ênfase discursiva na mensuração do desempenho de alunos, corre-se o risco de responsabilizá-los (bem como a seus professores e a suas escolas), obliterando o dever do Estado em garantir uma educação de qualidade. Tal movimento é reforçado por uma leitura psicologizante do desenvolvimento e apresenta-se como um mecanismo de segregação e exclusão pedagógica.

PALAVRAS-CHAVE QUALIDADE DA EDUCAÇÃO •IDEB • PISA • DESEMPENHO ACADÊMICO. 


\section{RESUMEN}

Este artículo analiza, por medio de un enfoque foucaultiano, las incongruencias del discurso sobre la calidad de la educación en Brasil a partir de dos instrumentos de verificación: el Índice de Desarrollo de la Educación Básica y el Programa Internacional de Evaluación de Estudiantes. A pesar del destaque para la necesidad de mejorar los procesos de escolarización, con un avance de las discusiones y su constante inserción en la agenda de las políticas públicas en diversas esferas, el propio sistema crea celadas que pueden comprometer su viabilización. Cuando se simplifica la cuestión, por un énfasis discursivo en la mensuración del desempeño de los alumnos, se corre el riesgo de responsabilizarlos (así como a sus profesores y a sus escuelas), obliterando el deber del Estado de garantizar una educación de calidad. Tal movimiento es reforzado por una lectura psicologizante del desarrollo y se presenta como un mecanismo de segregación y exclusión pedagógica.

PALABRAS CLAVES CALIDAD DE LA EDUCACIÓN • IDEB • PISA • DESEMPEÑO ACADÉMICO.

\section{ABSTRACT}

This paper analyzes, under a foucauldian framework, the incongruences of the discourse on education quality in Brazil, based on two assessment tools: the Basic Education Development Index and the Programme for International Student Assessment. Despite the emphasis on the need for improvements on the schooling processes, given how the discussions have advanced and how they are often part of the agenda pertaining to public policies in numerous spheres, the system itself sets pitfalls that can jeopardize their implementation. When the issue is simplified, by means of a rhetoric emphasis placed on measuring the students' performance, there is a risk of putting the blame on them (as well as their teachers and schools), negating the state's duty in guaranteeing quality education. Such movement is reinforced by a psychologizing take on development, presenting itself as a way of pedagogical exclusion and segregation.

KEYWORDS EDUCATION QUALITY • IDEB • PISA • ACADEMIC PERFORMANCE. 


\section{INTRODUÇÃO}

Qualidade: palavra oriunda do latim qualitas, empregada para indicar propriedade, natureza, estado, condição, cuja expressão interrogativa (qualis) permite a indagação: qual? De que tipo? De que maneira? Neste artigo partimos do princípio de que a compreensão dos elementos que qualificam um projeto educacional não é tarefa fácil. De qual projeto falamos? A que tipo de qualidade em educação nos referimos? De que maneira definir qualidade em educação?

Uma parcela da bibliografia produzida sobre o tema alerta-nos sobre a polissemia e complexidade da questão, como apontado por Araújo e Oliveira (2005), Dourado (2007), Oliveira (2007), Alavarse, Bravo e Machado (2013). São múltiplas abordagens e diferentes fatores que devem ser levados em consideração no tratamento do assunto, e partiremos dessa premissa neste texto. Entretanto, pretendemos assinalar que, a despeito da consideração das várias dimensões que precisam compor este debate, com a inclusão de uma análise que contemple a perspectiva histórica, política, financeira e administrativa de práticas pedagógicas, existe uma 
incongruência no discurso sobre qualidade da educação atual, uma desproporcionalidade nos pesos atribuídos aos fatores que interfeririam no sucesso ou no fracasso do processo educativo, a partir da ótica da interpretação dos resultados de provas standard como indicadores de qualidade da educação.

Por meio de observações sobre o discurso presente no texto "Índice de Desenvolvimento da Educação Básica (Ideb)" (FERNANDES, 2007) e no website da Organização para Cooperação e Desenvolvimento Econômico (OCDE, 2011), buscaremos assinalar de que forma a complexidade da questão sobre qualidade da educação é reduzida quando se relega, a segundo plano, uma discussão sobre como avaliações padronizadas deveriam servir não apenas para mensurar o desempenho de estudantes e escolas, mas também para a sustentação de uma análise complexa da performance da execução das próprias políticas públicas educacionais, que precisam implantar programas para assegurar a presença de qualidade e equidade na educação. O que acaba por se destacar nos textos analisados é uma ênfase no desempenho dos alunos nas provas (em que as notas seriam a expressão de certa capacidade cognitiva) e uma tendência à responsabilização deles (e de suas famílias, suas escolas, seus professores) pelos maus resultados.

Quando qualidade da educação passa a ser destacadamente uma questão de meritocracia individual, ocorre uma descaracterização de um direito social, por meio do qual o Estado deveria assegurar patamares mínimos de igualdade, combatendo as irregularidades num sistema de ensino básico que se divide em público e particular, em que alunos provenientes do segundo recebem, a priori, um ensino de maior qualidade, impactando o ingresso, por exemplo, nas disputadas universidades públicas. Ou ainda, para garantir esse direito, seria preciso ampliar o questionamento sobre as desigualdades existentes na própria rede pública de ensino, na qual algumas unidades destacam-se, a título de exceção, como ilhas de excelência, enquanto outras amargam com condições precaríssimas de funcionamento.

No artigo 206 da Constituição Federal de 1988, a garantia de padrão de qualidade aparece como um dos

O Estado não pode responsabilizar os cidadãos pelo não principios a serem seguidos pelas cumprimento do dever de assegurar qualidade na educação, ${ }^{1} \begin{aligned} & \text { escolas brasileiras no processo de } \\ & \text { ensino. }\end{aligned}$ 
mas pode, inclusive, ser acionado judicialmente por qualquer um que se sinta lesado em relação a esse direito. Dessa forma, uma leitura reducionista sobre a questão da qualidade da educação traz riscos não apenas ao sucesso do processo de ensino e de aprendizagem, mas ao próprio princípio de educação (de qualidade) como direito público subjetivo, assegurado pela Constituição Brasileira de 1988, em seu artigo 208, parágrafo $1^{\circ}$ : "O acesso ao ensino obrigatório e gratuito é direito público subjetivo” (BRASIL, 1988).

[...] o direito público subjetivo confere ao indivíduo a possibilidade de transformar a norma geral e abstrata contida num determinado ordenamento jurídico em algo que possua como próprio. A maneira de fazê-lo é acionando as normas jurídicas (direito objetivo) e transformando-as em seu direito (direito subjetivo). (DUARTE, 2004, p. 113, grifo do autor)

Conforme dados preliminares do censo escolar de 2013

2 "Os resultados referem-se à matrícula inicial na creche, pré-escola, ensino fundamental e ensino médio, no ensino regular e na educação de jovens adultos [...] nas redes estaduais e municipais, urbanas rurais em tempo parcial e integral".
(BRASIL, s.d.), ${ }^{2}$ 40.366.236 estudantes estão matriculados em escolas estaduais e municipais no Brasil, e isso representa um enorme contingente populacional que pode frequentar os bancos escolares, o que é uma conquista social a ser preservada, mas não é suficiente.

Gostaríamos de chamar atenção para o fato de que, na letra da lei, o direito público subjetivo está vinculado ao acesso ao ensino. Dessa forma, o cumprimento do direito ocorrerá apenas quando houver acesso não apenas à instituição escolar, mas ao ensino significativo e de qualidade. Não há aprendizado que possa ser cobrado se não houver ensino!

Para que possa haver a reivindicação desse direito público subjetivo, é preciso que o cidadão o conheça e perceba quando está sendo violado. Embora exista toda uma maquinaria ideológica que alimenta o desconhecimento de que a qualidade na educação é um direito, é preciso que ampliemos e possamos colocar em circulação uma crítica em relação ao processo de naturalização de alguns mecanismos de exclusão escolar por meio de uma obliteração da lei. Para ilustrar esse movimento, apresentaremos algumas considerações sobre a complexidade e polissemia do termo qualidade em educação, noções que aparecem pouco contempladas 
no discurso dos textos analisados sobre o Índice de Desenvolvimento da Educação Básica (Ideb) e o Programa Internacional de Avaliação de Estudantes (Pisa), pois entendemos que a redução da problemática é gerada e mantida por uma ênfase no conceito de desempenho de alunos em avaliações padronizadas, que, quando utilizado em um viés psicologizante, traduzindo-o como expressão de habilidades e capacidades cognitivas, cumpre uma função de individualização de questões políticas e sociais, a serviço de uma forma de governamentalidade que prima pela disciplinarização e docilização populacional $^{3}$ (FOUCAULT, 2002).

POLISSEMIA E COMPLEXIDADE NA COMPREENSÃO DO TERMO “QUALIDADE EM EDUCAÇÃO”

Araújo e Oliveira (2005) destacam como as concepções sobre o que seria qualidade na educação mudam de perspectiva, a partir do movimento de democratização do acesso à escola que vem ocorrendo nos últimos quarenta anos na história da educação pública brasileira. Os autores identificam três momentos: primeiramente, a noção de qualidade na educação estava vinculada ao próprio processo de

3 No Vocabulário de Foucault encontramos a seguinte consideração: "A governamentalidade moderna coloca pela primeira vez o problema político da 'população', não a soma de sujeitos de um território, o conjunto de sujeitos de direito ou a categoria geral de 'espécie humana', mas o objeto construído pela gestão política global da vida dos indivíduos (biopolítica). Essa biopolítica implica não somente uma gestão da população, mas um controle das estratégias que os indivíduos, em sua liberdade, podem ter em relação a eles mesmos e aos outros. As tecnologias de governamentalidade estão relacionadas ao governo da educação e à transformação dos indivíduos nas relações familiares nas instituições" (REVEL, 2002, p. 40). construção de escolas que comportariam uma população que historicamente esteve alijada dos bancos escolares. A entrada de grande volume de alunos de camadas populares, numa estrutura que continuou mantendo uma lógica de funcionamento elitizada, com altos índices de evasão e repetência, precipitou a associação da noção de qualidade a uma segunda tendência, relacionada à tomada de medidas de correção para distorções no fluxo escolar. Dentre essas ações, a criação de classes de aceleração, a organização do sistema educacional em ciclos e medidas de progressão continuada. A generalização de avaliações padronizadas desloca novamente a discussão sobre qualidade na educação para uma terceira abordagem, que não define propriamente esse conceito, mas que entende que a qualidade possa ser inferida por meio de resultados em provas, associando qualidade ao desempenho de alunos em exames nacionais e internacionais. 
Essas mudanças conceituais revelam não apenas uma transformação de conjuntura, mas um jogo de forças em que "os conceitos, as concepções e as representações do que vem a ser uma Educação de Qualidade alteram-se no tempo e no espaço" (DOURADO, 2007, p. 7) e são diretamente influenciados pela tensão entre as dimensões econômicas, sociais, políticas e culturais de uma dada coletividade. Esse movimento de alteração da noção de qualidade seria consequência de uma dinâmica de poder, tal como afirma Foucault:

Multiplicidade de correlações de forças imanentes ao domínio onde se exercem, e constitutivas de sua organização; o jogo que, através de lutas e afrontamentos incessantes as transforma, reforça, inverte [...]; enfim, as estratégias em que se originam e cujo esboço geral ou cristalização institucional toma corpo nos aparelhos estatais, na formulação da lei, nas hegemonias sociais. (1988, p. 88-89)

Corroborando essa perspectiva dinâmica e crítica de análise da modificação do conceito de qualidade da educação ao longo da história, Dourado (2007) e Alavarse (2013) destacam ainda a importância da inclusão de duas dimensões que são influenciadas diretamente por esse jogo de poder: os aspectos intraescolares - "currículo, formação docente, gestão escolar, avaliação da aprendizagem, condições de trabalho, infraestrutura das escolas, etc." - e extraescolares - "condições de vida da população, capital econômico, cultural e social das famílias dos alunos, entorno social da escola, distribuição de renda, violência, entre outros" (ALAVARSE; BRAVO; MACHADO, 2013, p. 30).

Diante de tal destaque à complexidade da questão, passemos então a analisar de que forma essa discussão sobre a multifatoriedade de elementos que qualificam a educação comparece em pressupostos que fundamentam a tendência atual de inferência a respeito da qualidade da educação por meio de resultados obtidos por alunos em avaliações padronizadas.

Dourado (2007) destaca a relevância de organismos multilaterais como a Organização das Nações Unidas para a Educação, a Ciência e a Cultura (Unesco), o Banco Mundial, a OCDE, a Comissão Econômica para América Latina e Caribe (Cepa), 
o Programa das Nações Unidas para o Desenvolvimento (PNUD) e o Fundo das Nações Unidas para a Infância (Unicef) no fomento e articulação de diretrizes para elaboração de políticas públicas educacionais em países em desenvolvimento. Segundo o autor, as concepções de qualidade que aparecem nos documentos norteadores desses organismos apresentam "alguns pontos em comum, como, por exemplo, a vinculação do conceito de qualidade à medição, rendimento e a indicação da necessidade da instituição de programas de avaliação da aprendizagem" (DOURADO, 2007, p. 12, grifos nossos).

A lógica da tríade "insumo-processo-resultados" articula a questão do custo e retorno do financiamento em educação com processos de avaliação que, em tese, deveriam identificar potencialidades e fragilidades das políticas educacionais e seus programas (que deveriam incluir a complexidade da questão da qualidade na educação), mas que obliteram a relevância da questão e alteram o foco da discussão quando os resultados obtidos são entendidos como métrica do desempenho dos estudantes (e não das políticas educacionais), de uma certa performance cognitiva, o que, por sua vez, indicaria o resultado de uma boa ou má estimulação de competências e habilidades por parte daqueles que exercem função educativa em casa ou na escola.

Essa vertente de leitura de resultados em avaliações padronizadas está em consonância com a lógica liberal na qual um princípio de alta produtividade e eficiência rege políticas econômicas atuais e impacta as formas de organização das famílias, das fábricas, das relações interpessoais e das escolas, que precisam talhar o "modelo" de homem desse nosso tempo, cujo projeto de educação - balizado em desempenho (individual) - está presente nos textos que analisamos, como veremos a seguir. Quando os resultados em processos avaliativos passam a ser vistos como produto de capacidades e esforço individual, a complexidade necessária para a compreensão da temática da avaliação e qualidade em educação aparece de forma bastante diluída.

A premissa que desenvolvemos neste artigo de que há um deslocamento da responsabilidade do Estado para o indivíduo na produção de um padrão de qualidade, por meio 
da ênfase na noção de desempenho, pode ser ilustrada não apenas pela análise do discurso de textos oficiais que definem parâmetros de avaliação, mas também pelo discurso da mídia, por ocasião da publicação dos resultados das avaliações padronizadas. Esse movimento coincide com a concepção foucaultiana de circularidade discursiva, difusora e mantenedora de dispositivos disciplinares - "Técnicas, estratégias e formas de assujeitamento diante do poder" (REVEL, 2002, p. 24, tradução nossa) -, de mecanismos de dominação. Vejamos, como de exemplo, algumas manchetes de artigos publicados sobre o Ideb e sobre o Pisa, em que a questão da análise sobre o sistema de ensino parece estar obstruída pelo reforço da noção maniqueísta de bons e maus alunos, boas e más escolas, ${ }^{4}$ medidos e classificados por notas e rankings.

- "Escolas estaduais são suspeitas de expulsar alunos para melhorar Ideb." (ESCOLAS..., 2013).

- "Alunos brasileiros de escolas públicas ficam atrás em avaliação internacional” (CIEGLINSKI, 2010).

- $\quad$ "50 melhores e 50 piores escolas da Rede Pública do país” (IDEB..., s.d.).

- "O Ideb na porta das escolas" (O IDEB..., 2011).

- "Estudantes brasileiros ficam em $54^{\circ}$ em ranking de 65 países” (RODRIGUES et al., 2010).

Uma chave importante para compreender esse processo de disciplinarização implícito no discurso sobre qualidade da educação, por meio de uma individualização da questão, está presente numa análise mais aprofundada dos sentidos do emprego do conceito de desempenho. Neste artigo, pretendemos destacar como essa manobra ideológica encontra respal-

5 Foucault define a biopolítica como uma estratégia de poder que surge entre o final do século XVIII e início do século XIX, cujo alvo seria o corpo dos indivíduos de uma dada coletividade, por meio da difusão de uma série de procedimentos a respeito da saúde (incluindo a saúde mental), da higiene, da alimentação, da sexualidade etc. Uma série de procedimentos normativos e normalizantes que, quando internalizadados e "naturalizados", cumprem uma função política de disciplinarização. do num processo de psicologização do cotidiano escolar, em que as notas obtidas em avaliações seriam a tradução de um desempenho cognitivo relacionado à estimulação de "competências e habilidades" individuais, como afirma Lajonquière (2001). A circulação de um discurso "psi" na educação pode ser entendida, a partir de Foucault (1988), como estratégia de construção e manutenção de uma modalidade de poder, o biopoder, ${ }^{5}$ que, articulado a um saber psicológico, disciplina, 
naturaliza e normatiza questões sociais e apresenta-se como uma modalidade de governo das populações.

O "mau desempenho cognitivo" seria indicador de uma suposta fragilidade nas estruturas psicológicas, traduzidas como competências e habilidades, não desenvolvidas ou não estimuladas pelas famílias e por professores, o que reforçaria a circulação de um discurso excludente, no qual o êxito escolar seria uma questão de mérito individual (e não um direito social), dessimplicando a responsabilização das esferas públicas e ferindo o direito público subjetivo à educação não apenas no que diz respeito ao acesso, mas também ao ensino de qualidade. Vejamos de que forma tais questões comparecem em textos que destacam Ideb e Pisa como norteadores da política atual de qualidade da educação no Brasil.

\section{A ÊNFASE NO DESEMPENHO DOS ALUNOS NA INTERPRETAÇÃO DE RESULTADOS DO IDEB E DO PISA}

Atualmente, o Ministério da Educação (MEC) pauta-se, sobretudo, nos resultados da aplicação de dois instrumentos para aferição da qualidade da educação brasileira e suporte na construção de suas políticas públicas: Ideb e Pisa. No decreto n. 6.094 de 24/04/2007 (BRASIL, 2007), que dispõe sobre a implementação do Plano de Metas Compromisso Todos pela Educação, ${ }^{6}$ o Ideb é apresentado em seu capítulo II como indicador objetivo para aferir a qualidade da educação básica, a partir dos dados combinados sobre rendimento dos alunos em avaliações nacionais e dados do censo escolar. As metas a serem cumpridas pelo Ideb são instituídas, por sua vez, em referência às médias internacionais obtidas pelos alunos no Pisa:

O Ideb (Índice de Desenvolvimento da Educação Básica) é o indicador objetivo para a verificação do cumprimento das metas fixadas no Termo de Adesão ao Compromisso “Todos pela Educação", eixo do Plano de Desenvolvimento da Educação, do Ministério da Educação, que trata da educação básica. É nesse âmbito que se enquadra a ideia das metas intermediárias para o Ideb. A lógica é a de que, para que o Brasil chegue à média 6,0 em 2021, período estipulado tendo como base a simbologia do bicentenário

6 Assim definido pela Assessoria de Comunicação Social do MEC: "O Plano de Metas Compromisso Todos pela Educação é a conjugação dos esforços da União, Estados, Distrito Federal e Municípios, em regime de colaboração, das famílias e da comunidade, em proveito da melhoria da qualidade da educação básica. Os sistemas municipais e estaduais que aderirem ao Compromisso seguirão 28 diretrizes pautadas em resultados de avaliação de qualidade e de rendimento dos estudantes". Disponível em: <http:// portal.mec.gov.br/arquivos/pdf/ diretrizes_compromisso.pdf>. Acesso em: 10 out. 2013. 
da Independência em 2022, cada sistema deve evoluir segundo pontos de partida distintos, e com esforço maior daqueles que partem em pior situação, com um objetivo implícito de redução da desigualdade educacional.

A definição de uma meta nacional para o Ideb em 6,0 significa dizer que o país deve atingir em 2021, considerando os anos iniciais do ensino fundamental, o nível de qualidade educacional, em termos de proficiência e rendimento (taxa de aprovação), da média dos países desenvolvidos (média dos países membros da OCDE) observada atualmente. Essa comparação internacional foi possível devido a uma técnica de compatibilização entre a distribuição das proficiências observadas no Pisa e no Saeb. (BRASIL, 2013)

Reynaldo Fernandes foi presidente do Instituto Nacional de Estudos e Pesquisas Educacionais Anísio Teixeira (Inep) entre 30 de setembro de 2005 e 21 de dezembro de 2009 e responsável pela criação do Ideb, assim definido em seu texto de 2007:

[...] um índice de desenvolvimento educacional que considere tanto informações de desempenho em exames padronizados como informações sobre fluxo escolar. $O$ indicador proposto é o resultado da combinação de dois outros indicadores: a) pontuação média dos estudantes em exames padronizados ao final de determinada etapa do ensino fundamental (4a e 8aㅗ séries) e 3o ano do ensino médio; e b) taxa média de aprovação dos estudantes da correspondente etapa de ensino. (FERNANDES, 2007, p. 16, grifo nosso)

O índice é apresentado como uma tentativa de correção de incoerências nas políticas educacionais que desvincularam fluxo escolar e aprendizado. Segundo Fernandes (2007), as políticas que priorizaram apenas o combate à repetência como medida de aprovação automática e progressão continuada resultaram na "redução da proficiência média dos alunos" (FERNANDES, 2007, p. 8). Para tanto, com o Ideb, é proposta uma correlação entre os dados sobre aprovação escolar, obtidos no censo escolar, e as médias de desempenho nas avaliações do Inep. 
Embora haja um destaque no texto sobre a importância do emprego do índice como revelador do desenvolvimento educacional das redes de ensino, quando o autor apresenta os aspectos conceituais sobre o Ideb, o foco do mesmo está no desempenho do aluno:

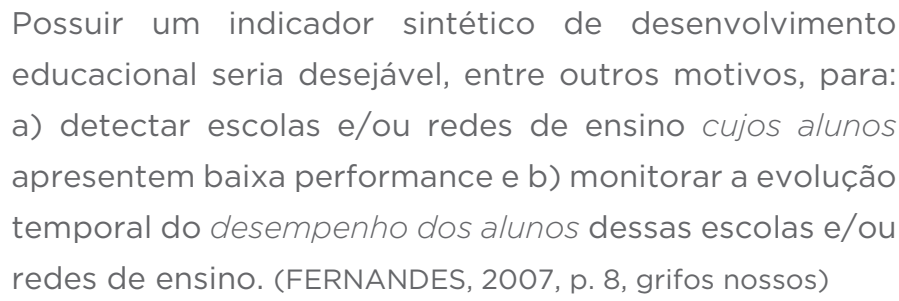

Na descrição dos elementos que compõem a fórmula para cálculo do Ideb aparece a correlação entre tempo esperado para a conclusão de uma etapa de ensino em uma determinada unidade (escola, rede de ensino, município) e a "proficiência esperada, em determinado exame padronizado, para estudantes da unidade ao final da etapa de ensino considerada" (FERNANDES, 2007, p. 10, grifos nossos). O autor entende proficiência como incremento na aquisição de habilidades e conhecimentos por parte dos alunos. O que o texto não contempla é exatamente de que forma as escolas, as políticas e o sistema educacional podem contribuir para o aumento da aprendizagem de nossos estudantes; mas certamente esse movimento não pode depender apenas do esforço, da vontade, do "amadurecimento" do aluno.

O Pisa, por sua vez, é um programa desenvolvido desde 2000 pela OCDE e busca estabelecer uma comparação sobre os sistemas educacionais a partir do resultado de questionários aplicados a gestores de unidades escolares e por meio de exames e questionários aplicados a uma amostragem de estudantes de quinze anos, de diferentes países, que aderiram ao programa. As provas são realizadas num espaço trienal e em cada edição há destaque a uma área de conhecimento: leitura, matemática ou ciências. Segundo a OCDE, o objetivo do Pisa é o de oferecer aos participantes uma possibilidade de comparação da "performance de seus alunos" em relação a diferentes países e economias e a progressão dos resultados ao longo do tempo (OCDE, 2013). O Inep, instituição respon- 
sável pela organização e aplicação do Pisa no Brasil, defende que os indicadores produzidos por esse exame deveriam contribuir para uma discussão ampla sobre a qualidade da educação nos países participantes, além de sustentar políticas educacionais. Entretanto, na descrição que o Inep faz dos marcos referenciais do Pisa, novamente encontramos uma ênfase na aprendizagem (no aluno), e não nos sistemas de ensino:

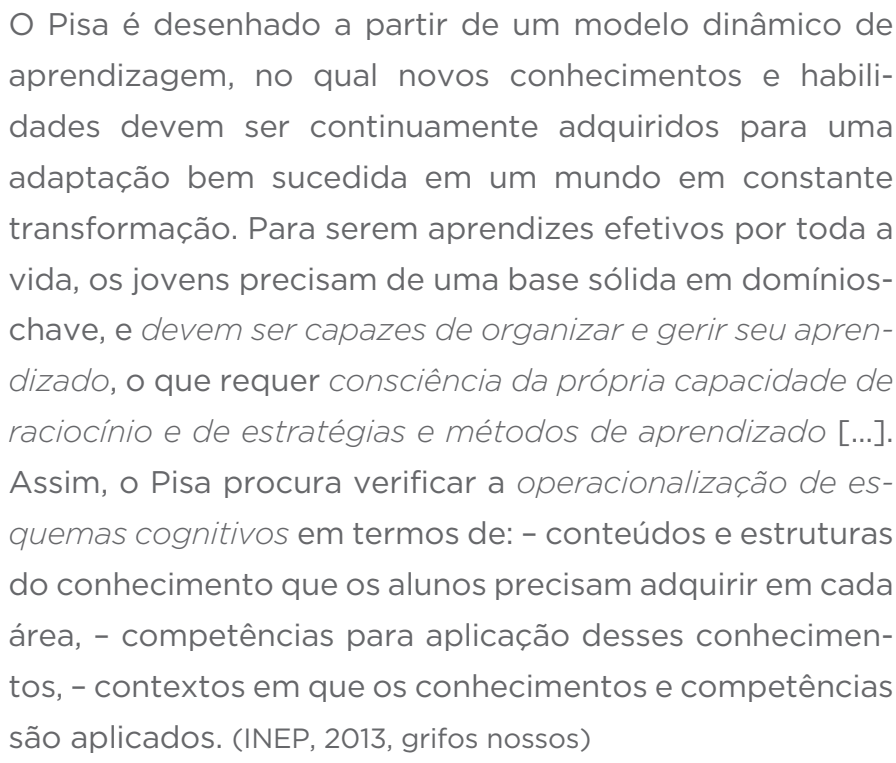

A citação acima remete a algumas questões apresentadas por Carvalho (2001) em sua análise sobre algumas distorções realizadas a partir de formulações sobre o construtivismo, considerado, a partir da década de oitenta no Brasil como alternativa ao ensino tradicional. Entretanto, um movimento de leitura superficial da teoria formulada por Piaget e Vygotsky e o emprego descontextualizado de alguns de seus conceitos produziu um efeito perverso de ausência de ensino e de interferência do professor nas atividades de alunos em muitas escolas, em razão de uma interpretação equivocada e reducionista da ideia de que é "a criança que constrói seu conhecimento", uma vez que esse movimento não ocorre sem intervenção, mediação. Da mesma forma, a ausência de considerações sobre os processos de ensino no texto do Inep sobre o Pisa pode induzir à percepção de que a capaci- 
dade de organização e gestão do aprendizado ou a tomada de consciência sobre a própria capacidade de raciocínio e estratégias e métodos de aprendizado depende apenas da operacionalização de esquemas cognitivos, ou seja, da inteligência do aluno, omitindo-se que esse processo não é espontâneo e depende de múltiplas interações.

Em sua webpage, a OCDE destaca que o Pisa não é uma avaliação escolar comum, porque não está ligada diretamente ao currículo escolar; em questões relacionadas a situações do dia a dia, o aluno é convidado a fazer uma aplicação de seus conhecimentos. ${ }^{7}$ Há um destaque para o fato de que o exame visa a medir "o grau de conhecimentos e habilidades que foram adquiridos e são essenciais para participação plena nas sociedades modernas" (OCDE, 2013). Essa afirmação é fundamentada no pressuposto de que "economias modernas recompensam indivíduos não pelo que sabem, mas pelo que podem fazer com o que sabem" (OCDE, 2013). Atentemos, então, para o fato, como mencionado anteriormente, de que há uma vinculação entre a mensuração de habilidades e competências "dos alunos" e sua capacidade produtiva, sem maiores questionamentos sobre como as próprias economias modernas se alimentam das irregularidades e da produção de sujeitos que podem fazer sem, no entanto, saber.

O processo de individualização da questão da qualidade da educação respalda-se numa certa concepção psicologizada do ato de aprender. A repetição das expressões "desempenho", "proficiência”, "performance", "capacidade de raciocínio”, "operacionalização de esquemas cognitivos" ilustra esse movimento que funde o processo de aprendizagem com o desenvolvimento de capacidades psicológicas. Nesse sentido, a segregação dos mais aptos (aqueles com maior "operacionalização" de habilidades e competências) daqueles menos produtivos será iniciada na infância pela escola, que encontrará nos constructos da psiquiatria e da psicologia, a partir do século XIX, fundamentos para identificação dos sinais indicadores de "problemas" no processo de desenvolvimento estabelecido como normal para um determinado aluno.

Uma alteração da própria concepção sobre o que é educar, na qual o processo de transmissão de conhecimentos 
é reduzido à aplicação de técnicas e estimulação de capacidades, habilidades e competências, será um dos fatores responsáveis pelo comprometimento do ato educativo. O "baixo desempenho" de alunos nas provas padronizadas não é capaz de revelar déficits e problemas de aprendizagem ou comportamento, mas é, sim, um forte indicador de ausência de ensino, mascarada muitas vezes numa leitura psicologizante. Formularemos, então, agora, algumas considerações sobre esse processo que a nosso entender produz um comprometimento progressivo da qualidade da educação.

\section{PSICOLOGIZAÇÃO DA EDUCAÇÃO E COMPROMETIMENTO DO ATO EDUCATIVO}

A pedagogia atual está imersa em um contexto de psicologização de seu cotidiano, no qual o aluno é convertido em um "sujeito psicológico" com supostas potencialidades "biopsicomaturacionais" que precisariam ser estimuladas e desenvolvidas (LAJONQUIÈRE, 2001). Nesse contexto, os saberes oriundos sobretudo do campo da psicologia do desenvolvimento constituem-se como "o fundamento" das práticas pedagógicas atuais que sustentam a aplicação de metodologias e determinam padrões de normalidade.

Na obra Hermenêutica do sujeito (2006a), Foucault critica a ideia do conceito de subjetividade como uma entidade natural. O "sujeito" é concebido a partir de distintos campos de conhecimento; há o sujeito da medicina, o sujeito da religião, o sujeito da psicanálise, o sujeito da filosofia moderna etc. O que o leva a afirmar que não existe um sujeito, mas apenas formas de subjetivação, modos de nomear e conceber o sujeito.

O estabelecimento de balizas de normalidade desse sujeito psicológico no ambiente escolar foi uma vertente fundamental na obra de Alfred Binet (1857-1911) e de seu discípulo Théodore Simon (1873-1961). Conforme sinaliza Jatobá (2002), “desde o final do século XIX, Binet vem apontando o interesse por questões ligadas à infância anormal e desempenho escolar" (JATOBÁ, 2002, p. 48, grifo nosso). Foi no campo da educação das crianças, então chamadas de 
anormais, que Binet pôde aplicar suas teses desenvolvidas no âmbito da psicometria ${ }^{8}$ e pôde estabelecer as "correlações que devem existir entre o desenvolvimento físico e 8 Área da psicologia que procura medir os fenômenos psíquicos. o desenvolvimento mental, perseguindo de uma maneira geral o estudo dos sinais físicos de inteligência” (BINET; SIMON, 1931, p. V, tradução nossa).

O foco de interesse do trabalho de Binet para com as crianças ditas anormais estará naqueles sujeitos tidos como débeis mentais, ou seja, nos que "não apresentam ausência completa de inteligência, mas não são suficientemente dotados para se beneficiarem de um trabalho comum com os normais" (BINET, 1907, p. 8, tradução nossa). Binet alertava, sobretudo quanto ao processo de escolarização desses sujeitos, que não deveria acontecer mais no interior dos hospitais, destinados às pessoas com desordens nervosas graves, mas em uma escola especial, com um "ensino adaptado à sua forma de inteligência, [...] de uma maneira metódica e completa, em classes pouco numerosas para permitir um ensino individual" (1907, p. 10). Essas classes seriam formadas tendo em vista resultados oriundos de testes psicométricos padronizados.

Essa ideia de adaptação do ensino ao "ritmo de desenvolvimento da criança" e o pressuposto de que classes homogêneas favorecem o desempenho dos alunos produziram um encantamento não só nos educadores das escolas especiais, mas à pedagogia de modo geral, sobretudo com o impulso fornecido pelos ideais educativos do movimento escolanovista (COTRIN, 2010). A própria noção de desenvolvimento como uma sucessão de fases com maior nível de complexidade das funções mentais, as quais deveriam ser alcançadas numa determinada idade, impulsionou a organização do currículo escolar em uma progressão que deveria atender as necessidades dos alunos em cada período de sua vida. Claparède (1873-1940), aluno de Binet, traduziu essas inquietações sobre a necessidade de transformação dos sistemas escolares de modo a produzir uma forma de ensino adaptada às necessidades infantis.

Em seu texto A escola sob medida (1953), Claparède propõe uma sobredeterminação entre desenvolvimento e educação 
(a partir dos conceitos de "ritmo", "produção", "desempenho"), já que é claro ao afirmar que a função da escola (muitas vezes reduzida ao desenvolvimento de aptidões, competências e capacidades) é levar em consideração as características individuais de forma a desenvolver em cada um suas aptidões "naturais".

Foucault (2002) afirma que foi graças a essa criança anormal que a psiquiatria infantil surgiu, isto é, buscando determinar as bases fisiológicas e morais das anomalias e determinando as escalas normais de desenvolvimento. Caberia à educação ponderar o rendimento escolar da criança (em referência à idade cronológica e ritmo) e buscar detectar indícios de anormalidade ou possíveis problemas de desenvolvimento. Assim, não apenas os alunos encaminhados para as classes especiais receberiam esse olhar meticuloso, pois esse procedimento de observação da adequabilidade do desenvolvimento infantil dentro de padrões de normalidade estabelecidos generalizou-se para todas as crianças, uma vez que qualquer uma poderia tornar-se anormal devido à ausência de estimulação adequada ou alguma "degeneração mental". Essa teria sido a porta de entrada para a consolidação dos saberes oriundos do campo da psicologia e da psiquiatria como fundamento de concepções e práticas pedagógicas.

Quando pensamos no aluno que hoje é considerado como aquele com baixo desempenho acadêmico, com pouca “operacionalização de esquemas cognitivos” ou com pouco desenvolvimento de habilidades e competências para o trabalho escolar, devemos levar em consideração que estamos falando de um "sujeito psicológico" construído a partir de estruturas de biopoder e suas formas de subjetivação, que criaram o solo no qual foi possível o aparecimento e o governo não somente desse aluno tido como fracassado, mas também da noção de família desajustada, da criança problemática, do adolescente instável, do funcionário improdutivo; enfim, uma forma de descrever os fenômenos humanos a partir do crivo da normalidade estabelecida por critérios "científicos" oriundos das áreas médica e psicológica. A biopolítica permite a difusão da modalidade de poder apontada por Foucault (2006b) como poder disciplinar. Vivemos num 
contexto social ordenado por uma disciplina internalizada que, de forma capilar, determina nossas ações e pulveriza o temor da exclusão oriunda de uma anormalidade tida como sinônimo de patologia seja ela física ou mental.

Segundo Lima (2004) e Rose (1998), alguns manejos foram necessários para que houvesse o surgimento desse solo biopolitizado e desse sujeito disciplinar. Esses autores, seguindo uma orientação foucaultiana, entendem que essas manobras estão relacionadas com uma alteração no modo de governo das populações. Essa noção de governo extrapola uma concepção política de administração estatal e está relacionada a uma gerência da população "macro e microcosmicamente" (LIMA, 2004, p. 31). Esta só foi possível devido ao desenvolvimento de dois campos epistêmicos, a economia política e a estatística, e a partir do momento em que o conhecimento dos hábitos de vida populacional tornou-se alvo de interesse da administração pública, com o objetivo de incremento de controle sobre a vida pública e privada dos cidadãos.

Para Foucault (2002), a noção de governamentalidade está relacionada a uma replicação de técnicas que em diferentes lugares, no dia a dia, reproduzem a função de governar, determinando condutas e ações. Todas as palavras, expressões, termos técnicos, modos de instrução, feedbacks e avaliações que nomeiam e definem esse cotidiano não são reflexos de nossas experiências, mas produtoras elas mesmas dessas experiências que, uma vez internalizadas e incorporadas aos nossos modos de vida e às formas como nos reconhecemos, parecem incontestavelmente naturais.

Segundo Rose (2001), todas essas tecnologias ${ }^{9}$ seriam tentativas pragmáticas para instalação de um modelo único de indivíduo com um ideal ético que atravessaria diferentes locais e práticas. Agora perguntamos: que balizas são essas

Rose define tecnologia como "qualquer agenciamento ou qualquer conjunto estruturado por uma racionalidade prática e governado por um objetivo mais ou menos consciente" (2001, p. 38). que determinam, por exemplo, o que é um bom ou mau desempenho numa avaliação padronizada?

Ainda conforme as ideias de Rose (2001), não podemos deixar de lado o estabelecimento de uma relação entre a positividade e prescrição dos saberes "psi" e as políticas econômicas, sobretudo na lógica da economia liberal e sua propaganda, na 
qual somos indivíduos "livres" (para consumir, para trabalhar, para produzir, para andar conforme regras e normas).

Existe a tentação em muitos regimes de subjetivação, a enfatizar os elementos de autodomínio e as restrições, em detrimento de nossos próprios desejos e instintos - a exigência para que controlemos ou civilizemos uma natureza interior considerada excessiva. (ROSE, 2001, p. 44)

Os campos de conhecimento "psi" apresentam-se sobretudo como uma forma particular de expertise da conduta humana.

10 DELEUZE, G. Foucault Minneapolis: University of Minnesota Press, 1992.
Fazendo referência a Deleuze (1992), ${ }^{10}$ Rose (2001) demonstra que essa "interioridade" que os profissionais "psi" buscam desvendar não seria a expressão "natural" do psiquismo humano, mas a manifestação de uma série de injunções, conselhos, técnicas, hábitos de pensamento, rotinas e normas, que vieram de uma exterioridade a ser plissada e introjetada. Na perspectiva de Rose (2001), aqueles sujeitos que se recusam a se reconhecer nas designações que lhes são inculcadas são indicados como quem deve "ter algum problema interno"; diagnóstico a ser desdobrado em exames, testes e opiniões de especialistas. Numa perspectiva foucaultiana, talvez esses sujeitos, enquadrados num lugar de anormalidade, estejam apenas fazendo resistência a esse poder de construção de nossa identidade e denunciando uma construção ideológica.

No que diz respeito ao governo da subjetividade infantil, vemos como esse processo é atravessado pelo histórico escolar da criança, como se fosse determinante a correlação entre o bom aluno (ou o aluno ajustado à escola) e o bom cidadão (ou o cidadão ajustado). A partir do século XIX, é difícil desvincular a imagem de criança da de aluno. Do Ó (2003, p. 57) chega a afirmar que "a criança foi transformada em aluno”. É na escola que essas crianças serão submetidas a uma série de tecnologias que definem sua subjetividade e ao mesmo tempo generalizam a construção da ideia de criança psicologizada que deverá se enquadrar a um ritmo determinado e provar que está se "desenvolvendo" adequadamente. Esse discurso sobre a subjetividade e a identidade dos alunos não para de aumentar. Seu foco, mesmo camuflado, gira em 
torno do propósito de gerar alunos (futuros adultos) altamente produtivos. E aqueles que não entram na lógica desse discurso só podem estar com algum problema.

Segundo Lima (2004), a criação da noção de "criança-problema” deu margem à ampliação da vigilância e controle dos níveis de desenvolvimento de todas as crianças, porque, afinal, mesmo aquelas que estão momentaneamente ajustadas podem vir a enfrentar problemas futuros.

Esta denominação "criança-problema" teria surgido por volta de 1930 como forma de distinção daquelas consideradas "anormais" devido a fatores biológicos (como as classificadas como idiotas e imbecis). A criança tomada como problema teria se tornado anormal devido a alguma degeneração moral, demonstrando uma sobredeterminação entre os dois conceitos (criança anormal e criança-problema).

Segundo Silva (1951, p. 618):

Ao se estabelecer a distinção entre as crianças normais e anormais, cumpre que se tenha em vista não apenas aquelas que apresentam atraso mental, isto é, as idiotas, as imbecis, as simples retardadas, como também as que têm conduta irregular, revelando muitas vezes inteligência viva, mas acusando comprometimento das faculdades morais e anomalias do caráter. Assim, toda criança que apresenta um atraso de inteligência reconhecidamente inferior à média das crianças da mesma idade, ou que tenha comportamento irregular, denunciando anomalia moral, diz-se que é uma anormal.

Nesse contexto, não só a criança, mas toda a família deveria ser alvo de cuidados higiênicos, médicos, pedagógicos e psicológicos, e caberia à escola a função de "detecção precoce" de sinais que pudessem indicar qualquer alteração comportamental ou patologia psicológica. Mas, baseado em que parâmetros, o professor identificaria esses sinais? Conforme Lourenço Filho (1962), os professores deveriam ter conhecimento de psicologia e desenvolvimento infantil. Esse pressuposto pode hoje ser reconhecido na alta procura dos docentes por uma formação em psicopedagogia e na demanda por cursos e palestras ministradas por profissionais "psi". 
Os saberes "psi" também têm lugar importante na emissão dos atestados de normalidade: laudos e avaliações, obtidos por meio da aplicação de testes e experiências. A criança retratada pelos teóricos, sobre a qual se estabelecem determinados padrões de comportamento, fala ela mesma muito pouco. Interessante notar que a forma como se retrata essa criança e seus possíveis problemas reforça uma ideia de "natureza"; pouco se questiona as categorias que as descrevem, bem como a própria noção de subjetividade enquanto construção. A exterioridade do comportamento de uma pessoa é vista como reflexo de seu mundo interior. A psiquiatria moderna, a psicologia experimental e a pedagogia higienista, na virada do século XIX para o século XX, passaram então a buscar meios de confirmar essa premissa, como aprofundado por Bautheney (2011).

A progressiva psicologização do cotidiano escolar descaracteriza a função educativa quando se reduz à propagação de técnicas, de metodologias da moda, com um enfraquecimento da especificidade e criatividade do saber docente, relacionado à possibilidade de transmissão de conhecimento, abrindo verdadeiros "buracos" pedagógicos. $\mathrm{O}$ aluno, por sua vez, é cobrado a demonstrar conhecimento, no entanto, se não houve ensino, não haverá aprendizagem, mas mal-estar diante do fato de "não ter e ter que ter para dar", e ainda ser responsabilizado por tal situação.

\section{CONSIDERAÇÕES FINAIS}

Procuramos apresentar neste artigo algumas incongruências no discurso sobre qualidade da educação no Brasil. Dentre elas, destacamos que, a despeito de inúmeras considerações formuladas sobre a complexidade da questão, o debate a respeito é enfraquecido pela interpretação de resultados de avaliações padronizadas com ênfase no desempenho dos estudantes nas provas, amparada numa leitura psicologizante dos resultados como expressão do uso de supostas habilidades e capacidades cognitivas, como se as mesmas fossem entidades naturais e espontâneas.

Precisamos reconhecer que foram feitos avanços no que diz respeito ao acesso de alunos às escolas brasileiras, mas 
o direito à educação não pode ser reduzido à frequência aos bancos escolares, ele deve estar relacionado a um ensino de qualidade para todos. Concordamos com Prieto (2006), que assinala que o processo de inclusão escolar não deve ser um movimento destinado apenas ao aluno com deficiência; essa criança que não aprende na escola, porque não há ensino de qualidade, precisa ser incluída.

A necessidade de novas elaborações dos projetos (políticos) pedagógicos, de seu aprimoramento constante, da revisão das práticas de avaliação e de ensino (com especial atenção para relação professor-aluno) são algumas manobras destacadas por Prieto (2006) como fundamentais a serem realizadas "nas" instituições escolares "pelos" seus agentes, os quais sairiam, assim, de uma posição passiva de quem espera dos "especialistas" instruções sobre o seu saber fazer, assumindo uma posição de autoridade diante de sua prática profissional.

Tal perspectiva coincide com a posição de Souza (2010), a qual propõe que façamos uma substituição da análise dos fenômenos escolares sob o prisma dos "problemas de aprendizagem" pela introdução de um novo eixo analítico que verse sobre os "processos de escolarização", o que incluiria um espectro mais amplo do que o dos fenômenos que ocorrem em uma sala de aula e que são medidos em avaliações padronizadas, convocando um entendimento sobre as políticas públicas em educação e sobre como as mesmas são implantadas e vividas por gestores, educadores e alunos, numa contribuição mais efetiva para incremento da qualidade na educação.

\section{REFERÊNCIAS}

ALAVARSE, O. M.; BRAVO, M. H.; MACHADO, C. Avaliações externas e qualidade na educação básica: articulações e tendências. Estudos em Avaliação Educacional, São Paulo, v. 24, n. 54, p. 12-31, jan./abr. 2013.

ARAÚJO, G. C.; OLIVEIRA, R. P. Qualidade do ensino: uma nova dimensão da luta pelo direito à educação. Revista Brasileira de Educação, n. 28, p. 6-23, jan./abr. 2005.

BAUTHENEY, K. C. S. F. Transtornos de aprendizagem: quando "ir mal na escola" torna-se um problema médico e/ou psicológico. 2011. Tese (Doutorado em Educação) - Faculdade de Educação, Universidade de São Paulo, São Paulo. 2011. 
BINET, A. Les enfants anormaux. Paris: Librairie Armand Colin, 1907.

BINET, A.; SIMON, T. La mesure du développement de l'intelligence chez les jeunes enfants. Paris: Societé Alfred Binet, 1931.

BRASIL. Constituição (1988). Constituição da República Federativa do Brasil. Brasília, DF: Senado, 1988.

BRASIL. Decreto n. 6.094, de 24 de abril de 2007. Dispõe sobre a implementação do Plano de Metas Compromisso Todos pela Educação, pela União Federal, em regime de colaboração com Municípios, Distrito Federal e Estados, e a participação das famílias e da comunidade, mediante programas e ações de assistência técnica e financeira, visando a mobilização social pela melhoria da qualidade da educação básica. Brasília, 2007. Disponível em: <http://www.planalto.gov.br/ccivil/_Ato2007-2010/2007/Decreto/D6094.htm>. Acesso em: 13 out. 2013.

BRASIL. Instituto Nacional de Estudos e Pesquisas Educacionais Anísio Teixeira. Dados finais do Censo Escolar da Educação Básica de 2013 - Anexo I e II. s.d. Disponível em: <http://portal.inep.gov.br/basica-censo>. Acesso em: 10 dez. 2013.

O Pisa e o Ideb. Brasília: INEP, 2013. Disponível em:<http://portal. inep.gov.br/internacional-novo-pisa-opisaeideb>. Acesso em: 1 nov. 2013.

CARVALHO, J. S. F. Construtivismo: uma pedagogia esquecida da escola. Porto Alegre: Artes Médicas, 2001.

CIEGLINSKI, A. Alunos brasileiros de escolas públicas ficam atrás em avaliação internacional. Universo On Line, 7 dez. 2010. Disponível em: <http://educacao. uol.com.br/noticias/2010/12/07/alunos-brasileiros-de-escolas-publicas-ficamatras-em-avaliacao-internacional.htm>. Acesso em: 1 nov. 2013.

CLAPARÈDE, E. A escola sob medida. Rio de Janeiro: Fundo da Cultura, 1953.

COTRIN, J. T. D. Itinerários da psicologia na educação especial: uma leitura histórico-crítica em psicologia escolar. 2010. Tese (Doutorado em Psicologia Escolar e do Desenvolvimento Humano) - Instituto de Psicologia, Universidade de São Paulo, São Paulo. 2010.

DO Ó, J. R. O governo de si mesmo: modernidade pedagógica e encenações disciplinares do aluno liceal (último quarteto século XIX - meados do século XXI). Lisboa: Educa, 2003.

DOURADO, L. F. A qualidade da educação: conceitos e definições. Brasília: INEP, 2007.

DUARTE, C. S. Direito público subjetivo e políticas educacionais. São Paulo em Perspectiva, v. 18, n. 2, p. 113-118, abr.jun. 2004.

ESCOLAS estaduais são suspeitas de expulsar aluno para melhorar Ideb. G1, 28 maio 2013. Disponível em: <http:/g1.globo.com/goias/noticia/2013/05/ escolas-estaduais-sao-suspeitas-de-expulsar-alunos-para-melhorar-ideb.html>. Acesso em: 1 nov. 2013. 
FERNANDES, R. Índice de Desenvolvimento da Educação Básica (Ideb). Brasília: INEP, 2007.

FOUCAULT, M. História da sexualidade. Rio de Janeiro: Graal, 1988. v. 1: A vontade de saber.

Os anormais. São Paulo: Martins Fontes, 2002.

. A hermenêutica do sujeito. São Paulo: Martins Fontes, 2006a.

0 poder psiquiátrico. São Paulo: Martins Fontes, 2006b.

IDEB 2001. 50 melhores e 50 piores escolas da rede pública do país. Portal Terra, s.d. Disponível em: <http://www.terra.com.br/noticias/educacao/ infograficos/educacao-ideb/>. Acesso em: 1 nov. 2013.

O IDEB na porta das escolas. Estadão, 29 ago. 2011. Disponível em: < http:// www.estadao.com.br/noticias/geral,o-ideb-na-porta-das-escolas,765497,0. $\mathrm{htm}>$. Acesso em: 1 nov. 2013.

JATOBÁ, C. M. R. A sombra das escalas: um estudo sobre a concepção de anormalidade em Alfred Binet. 2002. Tese (Doutorado em Educação) Faculdade de Educação, Universidade de São Paulo, São Paulo. 2002.

LAJONQUIÈRE, L. Infância e ilusão (psico)pedagógica: escritos de psicanálise e educação. Petrópolis: Vozes, 2001.

LIMA, A. L. G. 0 espectro da irregularidade ronda o aluno: um estudo da literatura pedagógica e da legislação sobre a criança-problema. 2004. Tese (Doutorado em Educação) - Faculdade de Educação, Universidade de São Paulo, São Paulo. 2004.

LOURENÇO FILHO, M. B. Testes ABC para verificação da maturidade necessária à aprendizagem da leitura e escrita. São Paulo: Melhoramentos, 1962.

OLIVEIRA, R. P. Da universalização do ensino fundamental ao desafio da qualidade: uma análise histórica. Educação e Sociedade, v. 28, n. 100, p. 661-690, 2007.

ORGANIZAÇÃO PARA COOPERAÇÃO E DESENVOLVIMENTO ECONÔMICO - OCDE. Melhorando o desempenho a partir dos níveis mais baixos. OCDE, 2011. (Pisa em Foco, v.2). Disponível em: <http://www.oecd.org/pisa/pisaproducts/ pisainfocus/48488426.pdf>. Acesso em: 15 nov. 2013.

PRIETO, R. Atendimento escolar de alunos com necessidades educacionais especiais: um olhar sobre as políticas públicas de educação no Brasil.

In: ARANTES, V. (Org). Inclusão escolar: pontos e contrapontos. São Paulo: Summus, 2006. p. 31-103.

REVEL, J. Le vocabulaire de Foucault. Paris: Ellipses, 2002.

RODRIGUES, C. et al. Estudantes brasileiros ficam em $54^{\circ} \mathrm{em}$ ranking de 65 países. Útimo segundo, 7 dez. 2010. Disponível em: <http:/ultimosegundo.ig.com. br/educacao/estudantes+brasileiros+ficam+em+54+em+ranking+de+65+paises/ n1237852694731.html>. Acesso em: 1 nov. 2013. 
ROSE, N. Inventing our selves: psychology, power and personhood. Cambridge: Cambridge University Press, 1998.

Como se deve fazer a história do eu? Educação e Realidade, Porto Alegre, v. 26, n. 1, jan.jjun. 2001.

SILVA, A. C. P. Psiquiatria clínica e forense. Belo Horizonte: Renascença, 1951.

SOUZA, M. P. R. Retornando à patologia para justificar a não aprendizagem escolar: a medicalização e o diagnóstico de transtornos de aprendizagem em tempos de neoliberalismo. In: CONSELHO REGIONAL DE PSICOLOGIA DE SÃO PAULO; GRUPO INTERINSTITUCIONAL QUEIXA ESCOLAR. (Org.). Medicalização de crianças e adolescentes: conflitos silenciados pela redução de questões sociais a doenças de indivíduos. São Paulo: Casa do Psicólogo, 2010.

KATIA CRISTINA SILVA FORLI BAUTHENEY

Pós-doutoranda no Instituto de Psicologia da Universidade de São Paulo (IP/USP). Bolsista da Coordenação de Aperfeiçoamento de Pessoal de Nível Superior (Capes) katbau@usp.br 